\title{
Antioxidants in Varieties of Chicory (Cichorium intybus L.) and Wild Poppy (Papaver rhoeas L.) of Southern Italy
}

\author{
Anna Montefusco, Giuliana Semitaio, Pier Paolo Marrese, Andrea Iurlaro, \\ Monica De Caroli, Gabriella Piro, Giuseppe Dalessandro, and Marcello Salvatore Lenucci
}

\author{
Dipartimento di Scienze e Tecnologie Biologiche ed Ambientali (Di.S.Te.B.A.), Università del Salento, \\ Via Provinciale Lecce-Monteroni, 73100 Lecce, Italy \\ Correspondence should be addressed to Marcello Salvatore Lenucci; marcello.lenucci@unisalento.it
}

Received 25 November 2014; Accepted 3 March 2015

Academic Editor: Volker Böhm

Copyright (c) 2015 Anna Montefusco et al. This is an open access article distributed under the Creative Commons Attribution License, which permits unrestricted use, distribution, and reproduction in any medium, provided the original work is properly cited.

\begin{abstract}
We report the hydrophilic and lipophilic antioxidant activities, as well as the total phenol, flavonoid, tocochromanol (tocopherol and tocotrienol), and carotenoid contents in the edible portion of wild and cultivated varieties of chicory (Cichorium intybus L.) and in the basal rosette leaves of the wild species of poppy (Papaver rhoeas L.), known by natives as "paparina," collected in the countryside of Salento (South Apulia, Italy). We analyzed (1) two cultivars of chicory, the "Catalogna" harvested in the area between S. Pietro Vernotico and Tuturano (Brindisi) and the "Otrantina" harvested in Otranto (Lecce); (2) two wild chicory ecotypes harvested in S. Pietro Vernotico (Brindisi) and Statte (Taranto), respectively; (3) the basal leaves of wild poppy harvested in Sternatia (Lecce). In all samples, our results showed that the hydrophilic antioxidant activity is, generally, higher than the lipophilic activity. Poppy leaves exhibited the highest hydrophilic and lipophilic antioxidant activities and the highest concentration of total phenols and flavonoids. Tocopherols were detected only as traces. Among the extracted carotenoids, lutein and $\beta$-carotene were the most abundant in all analyzed samples. Total carotenoid content was greater in wild than in cultivated plants.
\end{abstract}

\section{Introduction}

Diet is one of the external factors with the greatest impact on growth, physical and mental development, performance, and productivity of humans. Epidemiological studies have shown that diets rich in plant foods, such as fruits, vegetables, legumes, and unrefined cereals, are of fundamental importance in the prevention of many diseases, such as cardiovascular, metabolic, neurodegenerative, chronic-degenerative, and inflammatory pathologies [1-4].

Beside carbohydrates, proteins, lipids, and essential micronutrients, edible plants also provide humans and animals a plethora of important phytochemicals. These molecules belong to various chemical classes, which are not synthesized by the human body, whose daily uptake with food, in sufficient doses, exerts effective biological activities, including that antioxidant [4-8].

Antioxidants are essential to protect molecules and biological systems by the action of deleterious free radicals, especially reactive oxygen species (ROS). The human organism is able to counteract the prooxidative activities of ROS due to the presence of an endogenous defense system, comprising the enzymes superoxide dismutase (SOD), catalase (CAT), and glutathione peroxidase (GPX), which provides mechanisms for the detoxification of peroxides and hydroperoxides in living cells [9]. However, when the ROS level exceeds the endogenous antioxidant capacity of the cell, an external supply of antioxidant molecules is required. This exogenous, nonenzymatic defence comes mainly from plant derived foods. Exogenous antioxidants include phenols, flavonoids, carotenoids, vitamins (C and $\mathrm{E}$ ), and reduced glutathione (GSH). Proper nutrition is, therefore, of chief importance as it provides an effective antioxidant defence system [10,11]. The Mediterranean diet is based on an abundant intake of fruits and vegetables; nevertheless recent studies have highlighted significant differences in the composition of the diet in various countries bordering the Mediterranean basin $[12,13]$. It is common, in fact, for some 
Mediterranean populations, such as those of Southern Italy and Greece, to enrich their daily diet with many different wild plants collected all year around [12]. Among these plants wild chicory and poppy both play an important role.

Common chicory (Cichorium intybus L.) is herbaceous plant belonging to the Asteraceae family. It spreads all over the world, especially in temperate regions of Eurasia and North America $[14,15]$. In Italy, it grows in all regions, including islands (Sardinia and Sicily), up to midmountain level $(800 \mathrm{~m})$. It is an extremely polymorphic species that has not been thoroughly studied, yet. Chicory is used in medicine since ancient times. It was, in fact, known and appreciated for its therapeutic properties by the Greeks and Romans. Many traditional uses have recently been confirmed by scientific evidence. Several studies carried out on chicory led to the identification and isolation of a wide variety of phytochemicals including anthocyanins [16], coumarins [17], flavonoids [18], fructans [19], and sesquiterpene lactones [20]. Both roots and shoots are used as food, but the most frequently consumed organs are the rosette basal leaves and stout young sprouts (turions) typical of some cultivated species, organs that are eaten raw or cooked. The wild poppy (Papaver rhoeas L.) or "corn poppy" is an annual herbaceous plant belonging to the Papaveraceae family. Wild poppy is native to the Middle East region and appeared in Europe with the introduction of cereal crops. It is, in fact, frequently found as weed in cereal fields and, more generally, in both cultivated and dry fallow or disturbed (ruderal) habitats [21]. Poppy seeds are used to flavor cakes, biscuits, and bread, while leaves, especially the younger basal rosettes, are widely used, mostly cooked, in the traditional cuisine of many Italian regions (in Salento, South Apulia, Italy, they are known by the term "paparina").

In this work the hydrophilic and lipophilic antioxidant activities, as well as the total phenol, flavonoid, tocochromanol (tocopherol and tocotrienol), and carotenoid contents in the edible portion of wild and cultivated varieties of chicory and in the basal rosette leaves of the wild species of $P$. rhoeas collected in the Salento countryside have been evaluated in order to gather useful information on the chemical characteristics of these species.

\section{Materials and Methods}

2.1. Chemicals. Tocotrienol and carotenoid standards were purchased from Cayman chemicals (Ann Arbor, MI, USA) and CaroteNature (Lupsingen, Switzerland), respectively. All other reagents and solvents were from Sigma-Aldrich (Milan, Italy).

2.2. Plant Material. The analyses were conducted on (1) two cultivars of chicory, the "Catalogna" harvested in the area between San Pietro Vernotico and Tuturano (Brindisi) (Figures 1(a) and $1(\mathrm{f})$ ) and the "Otrantina" harvested in Otranto (Lecce) (Figures 1(b) and 1(f)); (2) two wild chicory ecotypes, harvested in San Pietro Vernotico (Brindisi) and in Statte (Taranto), respectively (Figures 1(c), 1(d), and 1(f)); (3) the wild species of Papaver rhoeas, known by natives as "paparina," harvested in Sternatia (Lecce) (Figures 1(e) and 1(f)).
At least five plants were randomly collected for each typology to take into account intrapopulation variability and subsequently processed and assayed altogether as single replica. Sampling was repeated three times during the vegetative season (winter-spring 2012); each sampling constituted an independent replica. The plant material was identified by a local expert and a voucher specimen was desiccated, cataloged, and deposited in the herbarium of the Di.S.Te.B.A., Salento University, Lecce, Italy.

The freshly harvested plants were extensively washed with tap water and distilled water to remove soil particles. The edible portions were immediately homogenized in a blender (Waring Laboratory Science, Torrington, CT, USA) with liquid nitrogen. Aliquots of the homogenates were used to evaluate the hydrophilic and lipophilic antioxidant activity, as well as the total phenol, flavonoid, tocochromanol (tocopherol and tocotrienol), and carotenoid contents.

\subsection{Analytical Procedures}

2.3.1. Hydrophilic and Lipophilic Antioxidant Activity Assay. Hydrophilic and lipophilic antioxidant activities were evaluated by the TEAC (Trolox Equivalent Antioxidant Capacity) assay as described by Re et al., [22] using the ABTS decoloration method.

Hydrophilic and lipophilic antioxidants were extracted from $0.3 \mathrm{~g}$ of each homogenate (three independent replicates) with $100 \%$ methanol or $100 \%$ acetone, respectively, at $4^{\circ} \mathrm{C}$ under constant shaking $(300 \mathrm{rpm})$ for $20 \mathrm{~h}$. Samples were centrifuged at $8800 \mathrm{~g}$ for $7 \mathrm{~min}$. Supernatants were recovered and used for antioxidant activity measurements at $734 \mathrm{~nm}$ in a Beckman DU650 spectrophotometer (Beckman Coulter Ltd., High Wycombe, UK). Two different calibration curves were constructed using freshly prepared Trolox solutions for hydrophilic and lipophilic antioxidant activity determinations. The linear reading of the standard curves was from 0 to $16 \mu \mathrm{M}$ Trolox for both hydrophilic and lipophilic antioxidant activities. Values are expressed as $\mu \mathrm{M}$ of Trolox equivalents (T.E.)/100 g f.w.

\subsubsection{Determination of Total Phenol and Total Flavonoid Con-} tents. Phenols and flavonoids extraction was carried out in triplicate independent aliquots $(0.5 \mathrm{~g})$ of each plant typology by the method of Cantín et al., [23] slightly modified. Briefly, $1 \mathrm{~mL} 0.5 \mathrm{~N} \mathrm{HCl}$ in $80 \%$ aqueous methanol was added to the homogenate. The extraction was performed at $4^{\circ} \mathrm{C}$, for $16 \mathrm{~h}$, under constant shaking $(300 \mathrm{rpm})$; samples were then centrifuged at $13000 \mathrm{~g}$ for $20 \mathrm{~min}$.

Total phenols were determined according to the method reported by Xu et al. [24] on $50 \mu \mathrm{L}$ aliquots of the supernatant. The absorbance was read at $750 \mathrm{~nm}$ using a Beckman DU650 spectrophotometer. The linear reading of the standard curve was from 0 to $120 \mu \mathrm{g}$ gallic acid/mL and results are expressed in $\mathrm{mg}$ of gallic acid equivalents (G.A.E.) $/ \mathrm{kg}$ f.w.

The total flavonoid content was determined as described by Zhishen et al. [25] on $50 \mu \mathrm{L}$ aliquots of the supernatant. Samples were diluted with distilled water to a final volume of $0.5 \mathrm{~mL}$ and $30 \mu \mathrm{L}$ of $5 \% \mathrm{NaNO}_{2}$ was added. After $5 \mathrm{~min}$, $60 \mu \mathrm{L}$ of $10 \% \mathrm{AlCl}_{3}$ was added, followed, after further $6 \mathrm{~min}$, 


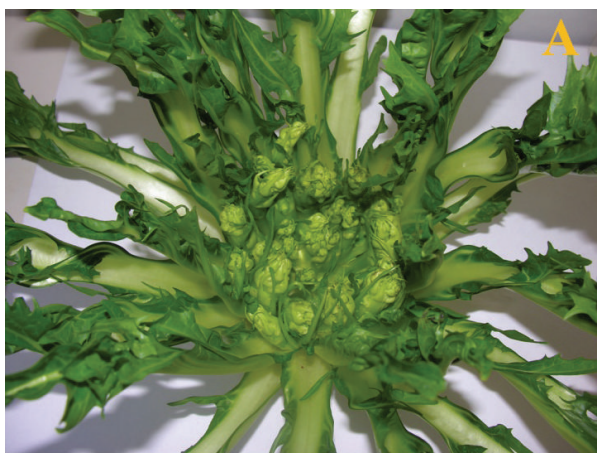

(a)

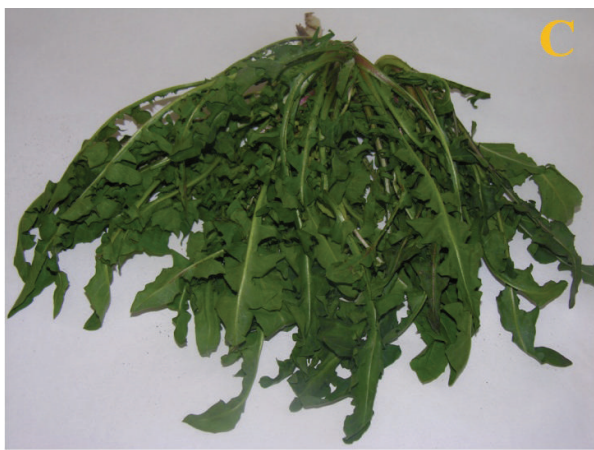

(c)

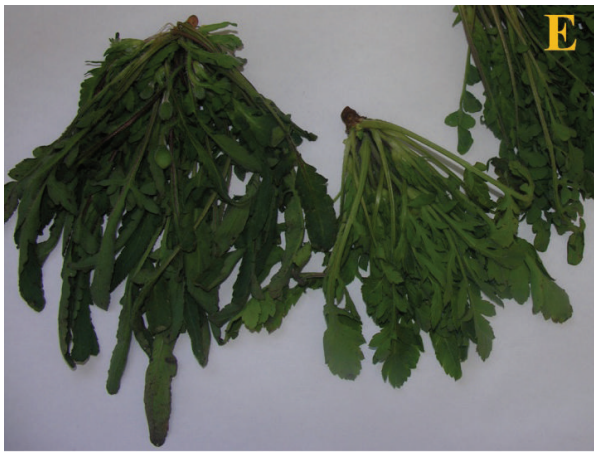

(e)

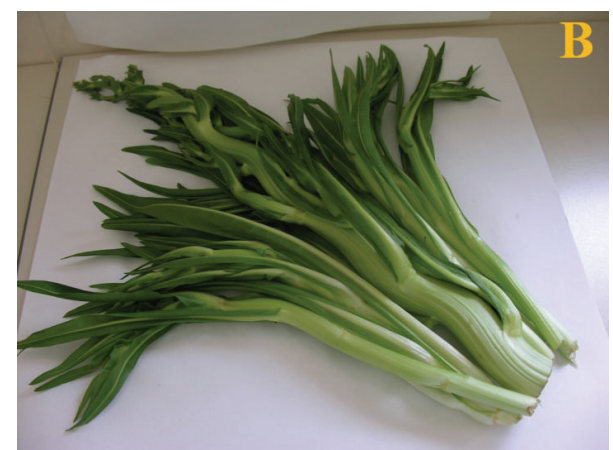

(b)

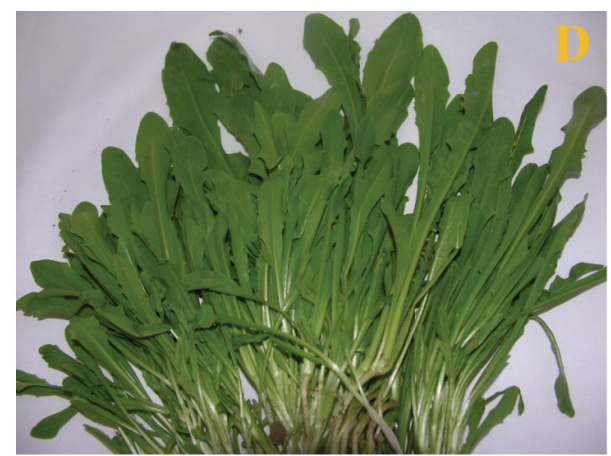

(d)

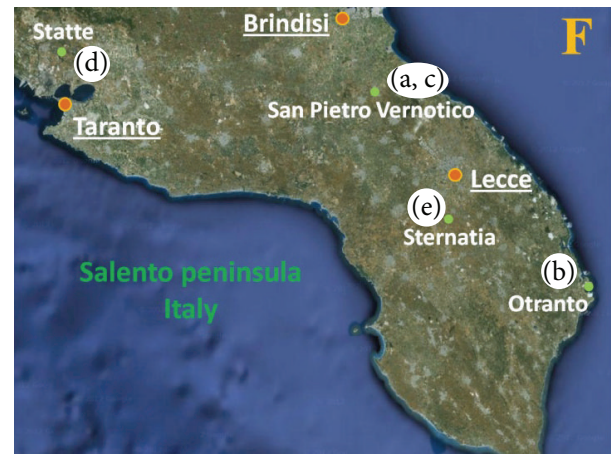

(f)

Figure 1: Photos of the analyzed plants: "Catalogna” chicory (a), "Otrantina" chicory (b), wild chicory from San Pietro Vernotico (c), wild chicory from Statte (d), and wild poppy (e); sampling sites (green spots) in the Salento Peninsula, Southern Italy (f).

by $200 \mu \mathrm{L}$ of $1 \mathrm{M} \mathrm{NaOH}$ and $210 \mu \mathrm{L}$ of distilled water. The absorbance was read at $510 \mathrm{~nm}$ in a Beckman DU650 spectrophotometer. The linear reading of the standard curve was from 0 to $400 \mu \mathrm{g}$ catechin $/ \mathrm{mL}$ and total flavonoid content was expressed as $\mathrm{mg}$ of catechin equivalents (C.E.) $/ \mathrm{kg}$ f.w.

2.3.3. Determination of Tococromanols and Carotenoids. Tocochromanol (tocopherols and tocotrienols) and carotenoid extraction was carried out as described by Fraser et al. [26] starting from $1.0 \mathrm{~g}$ of homogenate. Briefly, each homogenate was dissolved in $3 \mathrm{~mL}$ methanol and stirred at $4^{\circ} \mathrm{C}$ for $5 \mathrm{~min}$. After adding $3 \mathrm{~mL}$ of $1 \mathrm{M} \mathrm{NaCl}$ in $50 \mathrm{mM}$ TRIS $\mathrm{HCl}$ buffer $\mathrm{pH}$ 7.5 , the suspension was stirred for further $10 \mathrm{~min}$ at $4^{\circ} \mathrm{C} .8 \mathrm{~mL}$ of chloroform was added and the samples were vigorously stirred in an ice bath for $10 \mathrm{~min}$. Samples were centrifuged at $3000 \mathrm{~g}$ at $4^{\circ} \mathrm{C}$ for $5 \mathrm{~min}$ and the chloroform phase was recovered. The remaining material was reextracted with $8 \mathrm{~mL}$ of chloroform. The chloroform phases were combined and taken to dryness. The samples were analyzed by a Dionex high-performance liquid chromatography (HPLC) system equipped with an $\mathrm{AD} 25 \mathrm{UV}$-vis detector (Dionex s.r.l., Milan, Italy) and a Waters YMC Carotenoid $3 \mu \mathrm{m}$ column $(4.6 \times 250 \mathrm{~mm})$ (Waters Corporation, Milford, MA, USA) as described by Durante et al. [27]. Samples were prepared by dissolving the residues in ethyl acetate and filtering them through $0.2 \mu \mathrm{m}$ filters (Gelman Supor Acrodisc, Pall Corporation, Port Washington, NY, USA). The mobile phase was constituted by a mixture of methanol (A), $0.2 \%$ ammonium acetate aqueous solution/methanol (20/80, by volume) (B), and tert-methyl butyl ether (C). The solvents 
were mixed according to the following elution program: 0-12 min 95\% A, 5\% B; 12-45 min linear ramp from $80 \% \mathrm{~A}$, $5 \% \mathrm{~B}, 15 \% \mathrm{C}$ to $30 \% \mathrm{~A}, 5 \% \mathrm{~B}$, and $65 \% \mathrm{C}$; $45-55$ min linear ramp returning the system to the initial concentrations $(95 \%$ A, 5\% B); 55-65 min conditioning phase with 95\% A, 5\% B before each run. The flow rate was $1 \mathrm{~mL} \cdot \mathrm{min}^{-1}$. The samples were monitored at $290 \mathrm{~nm}$ (for tocopherols and tocotrienols) and $450 \mathrm{~nm}$ (for carotenoids); peaks were identified via comigration with authentic standards. All data obtained were related to the f.w. of the samples.

2.3.4. Statistical Analysis. Statistical analysis was based on a one-way ANOVA test. The post hoc method by HolmSidak was applied to establish significant differences between means with a confidence level of 95\%. Correlations were calculated using Pearson's correlation coefficient $(R)$. All statistical comparisons were performed using the SigmaStat Version 3.11 software (Systat Software Inc., Chicago, IL, US). All data represent the average of three independent replicates \pm standard deviation $(n=3)$.

\section{Results and Discussion}

The results of the hydrophilic, lipophilic, and total antioxidant activities, evaluated by the TEAC assay, in the edible part of different chicory varieties and wild poppy plants collected in the Salento countryside are shown in Figure 2. It should be noticed that, due to a partial overlap of the chemicals extracted with methanol and acetone, both hydrophilic and lipophilic antioxidant activities and consequently their sum to calculate the total antioxidant activity may be slightly overrated; nevertheless, the comparison among the samples still gives a proper idea of their overall rank. Given the above, the hydrophilic antioxidant activity (Figure 2(a)) was, generally, higher than the lipophilic (Figure 2(b)). Moreover, the wild poppy basal leaves exhibited the highest total antioxidant activity $(1326 \pm 23 \mu \mathrm{mol}$ TE/100 g f.w.) compared to all the assayed samples (Figure 2(c)). Several assays have been described to measure the antioxidant capacity of fruits and vegetables being the results strongly dependent on the product analyzed and on the method used [28, 29]; thus, comparison with other published data on chicory and wild poppy are hardly possible. Nevertheless, a higher antioxidant activity was found in $P$. rhoeas compared to that in $C$. intybus harvested in Spain by Morales et al. [8] with the DPPH and $\beta$-carotene bleaching methods.

Among the chicory varieties, the highest and the lowest total antioxidant activities were detected, respectively, in "Catalogna" (1056 $\pm 18 \mu \mathrm{mol} \mathrm{TE} / 100 \mathrm{~g}$ f.w.) and wild chicory ecotype harvested in San Pietro Vernotico $(352 \pm 13 \mu \mathrm{mol}$ TE/100 g f.w.) (which is thereafter indicated by "wild S.P.V."). The differences are probably due to the influence on the antioxidant activity by both varietal and environmental factors, the latter being related to growing, soil, and climatic conditions [5, 30]. Significant differences in the antioxidant activity between the two wild chicory ecotypes assayed were also found. The wild chicory harvested in Statte, Taranto (which is thereafter indicated by "wild Statte"), had hydrophilic, lipophilic, and total antioxidant activities, respectively, 90\%,

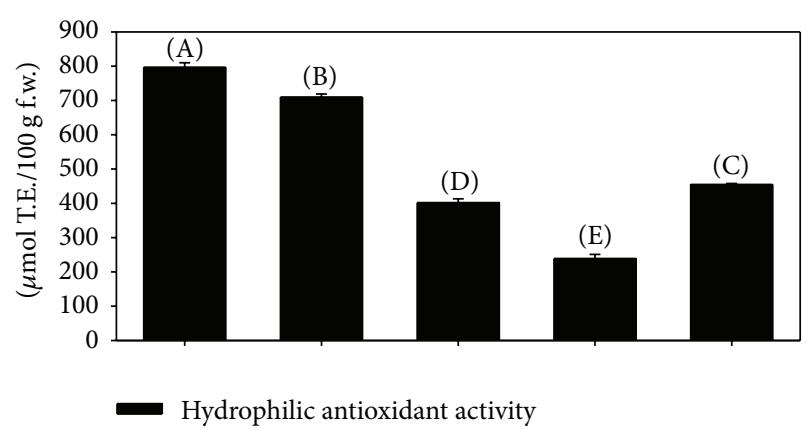

(a)

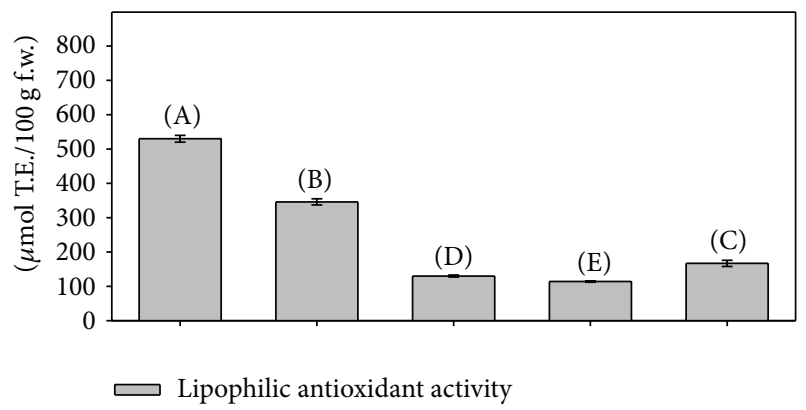

(b)

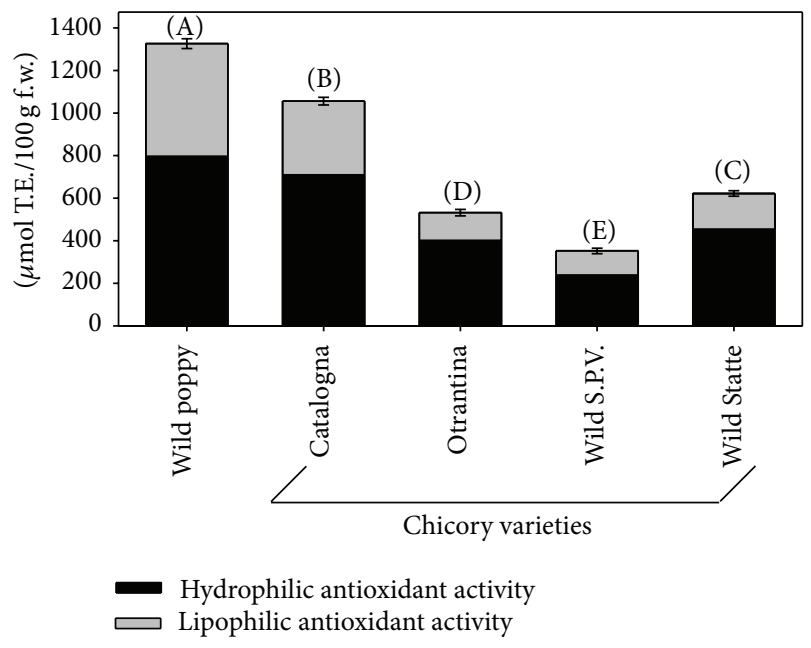

(c)

Figure 2: Hydrophilic (a), lipophilic (b), and total (c) antioxidant activity evaluated by the TEAC assay in different chicory varieties and wild poppy plants collected in Salento. Values are expressed as $\mu$ mol Trolox equivalent (T.E.) $/ 100 \mathrm{~g}$ f.w. and represent the mean \pm standard deviation of three independent replicates $(n=3)$. Data were submitted to one-way analysis of variance (ANOVA), and bars marked with different letters indicate significant differences among samples (Holm-Sidak post hoc test, $P<0.05$ ).

$46 \%$, and 77\%, higher than those of "wild S.P.V." likely due to environmental factors. Statte is, in fact, an area of high environmental pollution by heavy metals (mainly As, Cd, Fe, $\mathrm{Hg}, \mathrm{Ni}$, and $\mathrm{Pb}$ ) due the presence of ILVA, one of the largest iron-steel producer plants in Europe. It has been previously reported that the presence of toxic heavy metals, such as cadmium and zinc, in the soil can alter different metabolic 


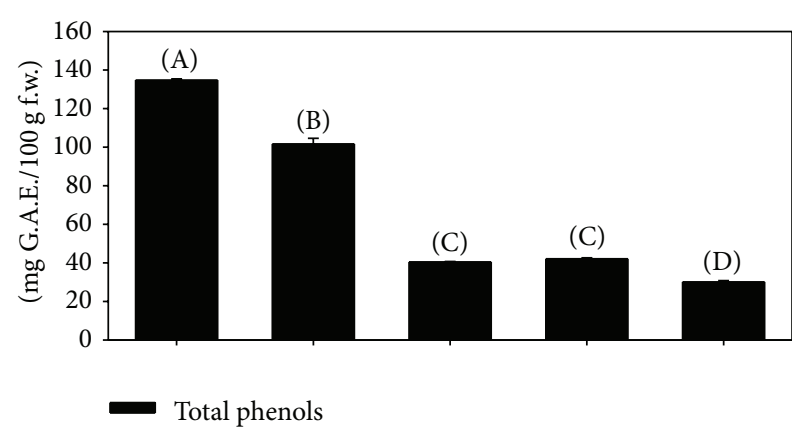

(a)

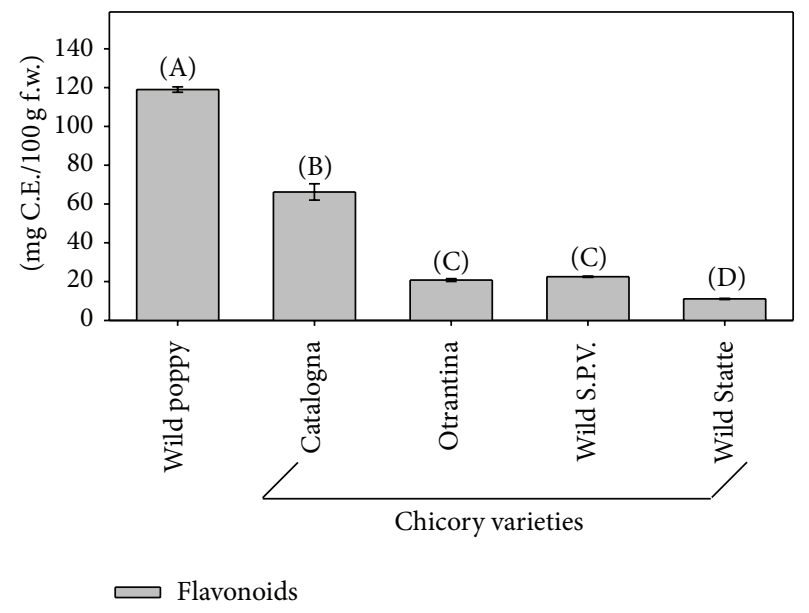

(b)

FIgURE 3: Total phenols (a) and flavonoids (b) in different chicory varieties and wild poppy plants collected in Salento. Total phenol values are expressed as $\mathrm{mg}$ gallic acid equivalent (G.A.E.) $/ 100 \mathrm{~g}$ f.w.; flavonoid values are expressed as $\mathrm{mg}$ catechin equivalent (C.E.) $/ 100 \mathrm{~g}$ f.w. and represent the mean \pm standard deviation of three independent replicates $(n=3)$. Data were submitted to one-way analysis of variance (ANOVA); bars marked with different letters indicate significant differences among samples (Holm-Sidak post hoc test, $P<0.05)$.

pathways generating oxidative stress. Oxidative stress may in turn influence the activity of some enzymes, such as catalase, peroxidase, and superoxide dismutase, whose induction is an important self-defense strategy against oxidation [31,32]. Stress may also affect secondary metabolism of plants leading to the production of antioxidant molecules [33].

Total phenolic content is shown in Figure 3(a). Among the chicory varieties, the highest value was obtained for "Catalogna" (101.7 $\pm 2.9 \mathrm{mg}$ GAE/100 g f.w.), followed by "wild S.P.V." and "Otrantina" (>40.5 mg GAE/100 g f.w.) and finally "wild Statte" (30.1 $\pm 0.7 \mathrm{mg}$ GAE/100 g f.w.). The values were in line with those reported by Innocenti et al. [18] and Sinkovič et al. [30] for green chicory cultivars but much lower than those reported by Saxena et al. [7] for chicory cultivated under control or severe drought stress conditions (650 and $420 \mathrm{mg}$ GAE/100 g f.w., resp.). These differences are likely due to many concurring biological and environmental factors (mainly light, temperature, and soil), as well as differences in the used analytical methods [34].
A detailed profile of phenols in the leaves of red, red-spotted, and green chicory cultivars cultivated in Slovenia has been recently published [30], indicating hydroxycinnamic acids, including chlorogenic and cichoric acids, as predominant phenolic compounds in all of the assayed samples. It has also been reported that chicory phenols have an extreme chemical stability even after cooking, thus increasing the alimentary interest for this plant [18]. Taking into account all the samples, the wild poppy exhibited the highest phenolic content ( $134.8 \pm 0.6 \mathrm{mg} \mathrm{GAE} / 100 \mathrm{~g}$ f.w.). This value was $24.6 \%$ higher than that found in "Catalogna" and similar to the amount found in samples harvested in Greece $(120 \mathrm{mg} / \mathrm{g})$, but approximately 4-fold higher and twofold lower than that found in poppy plants grown in two different Italian regions (Lucania and Calabria, resp.), indicating a strong impact of the geographical area on plant antioxidant composition [35].

A good correlation between total phenolics and hydrophilic ( $r=0.900 ; P=0.0375)$ or total antioxidant activity ( $r=0.945 ; P=0.0153$ ) was found (Table 2 ) accordingly with the reports of Chinnici et al. [36] and Tlili et al. [37] in cultivated plant fruits but in contrast to the observations of Parejo et al. [38] and Schaffer et al. [35] highlighting the lack of correlation between the antioxidant activity of Mediterranean plant extracts and their phenolics content.

The flavonoid content of the assayed plants is shown in Figure 3(b). The wild poppy leaves exhibited the highest flavonoid content $(119.0 \pm 1.4 \mathrm{mg}$ C.E./100 g f.w.). Among the chicory varieties, the highest value was obtained in "Catalogna" (66.2 $\pm 4.2 \mathrm{mg}$ C.E./100 g f.w.), while the lowest value was obtained in "wild Statte" $(11.1 \pm 0.3 \mathrm{mg}$ C.E./100 g f.w.). No correlation was found between total flavonoid content and hydrophilic antioxidant activity $(r=0.869$; $P=0.0556)$, while flavonoids well correlated with total antioxidant activity $(r=0.930 ; P=0.0219)$ (Table 2).

Tocochromanols (tocopherols and tocotrienols) and carotenoids have an important role in human diet; thus in this work their content was also evaluated. In all analyzed extracts, only traces of tocochromanols, mainly in the form of $\alpha$ - and $\gamma$-tocopherols, were detected, while significant amounts of carotenoids were found (Table 1). Concentration of total tocopherols of $29.8 \mu \mathrm{g} / \mathrm{g}$ f.w. and $18.7 \mu \mathrm{g} / \mathrm{g}$ f.w. was found by Morales et al. [8] in chicory and wild poppy, respectively, mainly in the chemical forms $\alpha$ and $\gamma$. Lutein and $\beta$-carotene have been widely reported as being two of the major carotenoids found in green leafy vegetables [39-41]. These two carotenoids were predominant also in the plants analyzed in our study, while the amount of $\beta$-cryptoxanthin was much lower. All carotenoids were mainly in the (allE)-isomeric form; no peaks corresponding to carotenoid (Z)-isoforms were detectable in significant amounts. Among chicory varieties, the highest amount of lutein was found in the two wild ecotypes with "wild Statte" $(30.1 \pm 4.5 \mu \mathrm{g} / \mathrm{g}$ f.w.) twice as high as "wild S.P.V." (14.7 $\pm 3.3 \mu \mathrm{g} / \mathrm{g}$ f.w.). Furthermore, wild poppy exhibited fairly high lutein content (18.4 $\pm 2.5 \mu \mathrm{g} / \mathrm{g}$ f.w.).

$\beta$-Carotene content ranged between $14.1 \pm 2.3 \mu \mathrm{g} / \mathrm{g}$ f.w. in "wild Statte" and $3.3 \pm 0.6 \mu \mathrm{g} / \mathrm{g}$ f.w. in "Catalogna." These values were lower than those reported in most of previous reports where $\beta$-carotene content ranged between 
TABLE 1: Carotenoid content in different chicory varieties and wild poppy plants collected in Salento.

\begin{tabular}{|c|c|c|c|c|c|}
\hline \multirow{2}{*}{ Carotenoids } & \multirow{2}{*}{ Wild poppy (Papaver rhoeas L.) } & \multicolumn{4}{|c|}{ Chicory (Cichorium intybus L.) varieties } \\
\hline & & Catalogna & Otrantina & Wild S.P.V. & Wild Statte \\
\hline (all-E)-Lutein & $18.4 \pm 2.5^{\mathrm{b}}$ & $8.0 \pm 0.9^{c}$ & $8.9 \pm 0.9^{c}$ & $14.7 \pm 3.3^{\mathrm{bc}}$ & $30.1 \pm 4.5^{\mathrm{a}}$ \\
\hline (all-E)- $\beta$-Cryptoxanthin & $0.29 \pm 0.02^{\mathrm{b}}$ & $0.14 \pm 0.03^{\mathrm{c}}$ & $0.13 \pm 0.03^{\mathrm{c}}$ & $0.28 \pm 0.01^{\mathrm{b}}$ & $0.41 \pm 0.05^{\mathrm{a}}$ \\
\hline (all-E)- $\beta$-Carotene & $8.9 \pm 0.5^{\mathrm{b}}$ & $3.3 \pm 0.6^{\mathrm{d}}$ & $4.6 \pm 0.7^{\mathrm{cd}}$ & $6.7 \pm 1.4^{\mathrm{bc}}$ & $14.1 \pm 2.3^{\mathrm{a}}$ \\
\hline
\end{tabular}

Values are expressed as $\mu \mathrm{g} / \mathrm{g}$ f.w. and represent the mean \pm standard deviation of three independent replicates $(n=3)$. Data were submitted to one-way analysis of variance (ANOVA); values marked with different letters indicate statistically significant difference between samples for a given carotenoid (Holm-Sidak post hoc test, $P<0.05)$.

TABle 2: Pearson's correlation coefficients $(r)$ and related significance between antioxidant activities and antioxidant content.

\begin{tabular}{|c|c|c|c|c|c|c|c|c|}
\hline & HAA & LAA & TAA & TPC & $\mathrm{TF}$ & Lut. & $\beta$-Cry. & $\beta$-Car. \\
\hline HAA & $*$ & & & & & & & \\
\hline LAA & $0.940^{*}$ & $*$ & & & & & & \\
\hline TAA & $0.989^{* *}$ & $0.981^{* *}$ & * & & & & & \\
\hline TPC & $0.900^{*}$ & $0.972^{* *}$ & $0.945^{*}$ & * & & & & \\
\hline $\mathrm{TF}$ & $0.869^{\mathrm{ns}}$ & $0.978^{* *}$ & $0.930^{*}$ & $0.986^{* *}$ & * & & & \\
\hline Lut. & $-0.067^{\mathrm{ns}}$ & $-0.035^{\mathrm{ns}}$ & $-0.054^{\mathrm{ns}}$ & $-0.250^{\mathrm{ns}}$ & $-0.165^{\mathrm{ns}}$ & * & & \\
\hline$\beta$-Cry. & $-0.135^{\mathrm{ns}}$ & $-0.028^{\mathrm{ns}}$ & $-0.090^{\mathrm{ns}}$ & $-0.213^{\mathrm{ns}}$ & $-0.122^{\mathrm{ns}}$ & $0.967^{* *}$ & * & \\
\hline$\beta$-Car. & $-0.071^{\text {ns }}$ & $-0.034^{\mathrm{ns}}$ & $-0.056^{\mathrm{ns}}$ & $-0.253^{\mathrm{ns}}$ & $-0.158^{\mathrm{ns}}$ & $0.997^{* * *}$ & $0.957^{*}$ & $*$ \\
\hline
\end{tabular}

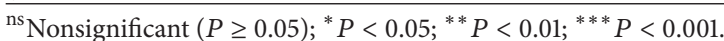

HAA: hydrophilic antioxidant activity; LAA: lipophilic antioxidant activity; TAA: total antioxidant activity; TPC: total phenolics, TF: total flavonoids; Lut.: (all-E)-lutein; $\beta$-Cry.: (all-E)- $\beta$-cryptoxanthin; $\beta$-Car.: (all-E)- $\beta$-carotene; TC: total carotenoids; $n$ (sample size): 5.

$73 \pm 11 \mu \mathrm{g} / \mathrm{g}$ f.w. and $39 \pm 7 \mu \mathrm{g} / \mathrm{g}$ f.w $[41,42]$. In green leafy vegetables, carotenoid content depends on several factors, including species and variety genotypes, agronomic and cultivation practices, and development and growth stage, as well as environmental factors such as light, temperature, and soil properties [41-43]. The results obtained in this work revealed that carotenoid content was greater in wild compared to that in cultivated plants and that carotenoid synthesis and accumulation can be strongly influenced by stress; wild chicory ecotype grown in the heavy metal contaminated soil of Statte showed, in fact, the highest amount of each single carotenoid. In a recent work, Sanità di Toppi et al. [44] reported that cadmium accumulation in carrot cell induces morphological alterations in chromoplasts and leads to an increased synthesis and accumulation of $\beta$-carotene. No correlation was found between lipophilic antioxidant activity and each single carotenoid (Table 2), suggesting that other acetone soluble molecules, such as fatty acids, quinones, and chlorophylls, contribute mostly to the observed lipophilic antioxidant activity of the leaf extracts.

\section{Conclusions}

In this work, we found that (1) the hydrophilic antioxidant activity was higher than the lipophilic antioxidant activity in analyzed different chicory varieties and wild poppy plants collected in Salento; (2) wild poppy basal leaves showed the highest antioxidant activity as well as the highest content of total phenols and flavonoids among the other assayed plants; (3) among the assayed chicory varieties, the "Catalogna" showed the highest antioxidant activity and the highest content of total phenolics and flavonoids; (4) lutein and $\beta$-carotene were the most abundant carotenoids in all analyzed samples; (5) the carotenoid content was higher in wild compared to that in cultivated species; (6) genotype and environmental factors both contribute to determining the antioxidant activity and the content of certain bioactive molecules.

Furthermore, the data reported here are useful for building knowledge on the chemical composition and antioxidant properties of these vegetables of food interest.

\section{Conflict of Interests}

The authors declare that there is no conflict of interests regarding the publication of this paper.

\section{References}

[1] N. McKeown, "Antioxidants and breast cancer," Nutrition Reviews, vol. 57, no. 10, pp. 321-324, 1999.

[2] A. Ronco, E. De Stefani, P. Boffetta, H. Deneo-Pellegrini, M. Mendilaharsu, and F. Leborgne, "Vegetables, fruits, and related nutrients and risk of breast cancer: a case-control study in Uruguay," Nutrition and Cancer, vol. 35, no. 2, pp. 111-119, 1999.

[3] S. Agarwal and A. V. Rao, "Tomato lycopene and its role in human health and chronic diseases," Canadian Medical Association Journal, vol. 163, no. 6, pp. 739-744, 2000.

[4] M. L. Slattery, J. Benson, K. Curtin, K.-N. Ma, D. Schaeffer, and J. D. Potter, "Carotenoids and colon cancer," The American Journal of Clinical Nutrition, vol. 71, no. 2, pp. 575-582, 2000.

[5] B. Carratù and E. Sanzini, "Sostanze biologicamente attive presenti negli alimenti di origine vegetale," Annali dell'Istituto Superiore di Sanità, vol. 41, no. 1, pp. 7-16, 2005. 
[6] O. Aruoma, "In vitro and in vivo methods for the assessment of antioxidant activity," in Proceedings of the EUROFOODCHEM 11th Meeting: Biologically-Active Phytochemicals in Food: Analysis, Metabolism, Bioavailability and Function, W. Pfannhauser, G. R. Fenwick, and S. Khokhar, Eds., Special Publication, No. 269, pp. 285-295, The Royal Society of Chemistry, Norwich Research Park, UK, September 2001.

[7] R. Saxena, K. B. Sulakhiya, and M. Rathore, "Cichorium intibus Linn.: a review of pharmacological profile," International Journal of Current Pharmaceutical Research, vol. 6, no. 4, pp. 11-15, 2014.

[8] P. Morales, I. C. F. R. Ferreira, A. M. Carvalho et al., "Mediterranean non-cultivated vegetables as dietary sources of compounds with antioxidant and biological activity," LWT-Food Science and Technology, vol. 55, no. 1, pp. 389-396, 2014.

[9] J. M. Matés, C. Pérez-Gómez, and I. N. de Castro, "Antioxidant enzymes and human diseases," Clinical Biochemistry, vol. 32, no. 8, pp. 595-603, 1999.

[10] E. Prenesti, S. Berto, P. G. Daniele, and S. Toso, "Antioxidant power quantification of decoction and cold infusions of Hibiscus sabdariffa flowers," Food Chemistry, vol. 100, no. 2, pp. 433438, 2007.

[11] A. M. Jiménez, M. Martínez-Tomé, I. Egea, F. Romojaro, and M. A. Murcia, "Effect of industrial processing and storage on antioxidant activity of apricot (Prunus armeniaca v. bulida)," European Food Research and Technology, vol. 227, no. 1, pp. 125134, 2008.

[12] A. Trichopoulou, E. Vasilopoulou, P. Hollman et al., "Nutritional composition and flavonoid content of edible wild greens and green pies: A potential rich source of antioxidant nutrients in the Mediterranean diet," Food Chemistry, vol. 70, no. 3, pp. 319-323, 2000.

[13] A. Trichopoulou, "Mediterranean diet: the past and the present," Nutrition, Metabolism and Cardiovascular Diseases, vol. 11, no. 4, pp. 1-4, 2001.

[14] L. Sinkovič, J. Hribar, D. Žnidarčičc, D. Treutter, and R. Vidrih, "Comparison of the phenolic profiles of forced and unforced chicory (Cichorium intybus L.) cultivars," Agriculturae Conspectus Scientificus, vol. 79, no. 2, pp. 133-137, 2014.

[15] L. Sinkovič, J. Hribar, R. Vidrih, Ž. M. Ilin, and D. Žnidarčič, "Fatty acid composition of leaves of forced chicory (Cichorium intybus L.)," Archives of Biological Sciences, vol. 1, 26 pages, 2015.

[16] R. Nørbæk, K. Nielsen, and T. Kondo, "Anthocyanins from flowers of Cichorium intybus," Phytochemistry, vol. 60, no. 4, pp. 357-359, 2002.

[17] V. G. Dem'yanenko and L. I. Dranik, "Coumarins of the racemes of Cichorium intybus," Chemistry of Natural Compounds, vol. 7, no. 1, p. 104, 1971.

[18] M. Innocenti, S. Gallori, C. Giaccherini, F. Ieri, F. F. Vincieri, and N. Mulinacci, "Evaluation of the phenolic content in the aerial parts of different varieties of Cichorium intybus L." Journal of Agricultural and Food Chemistry, vol. 53, no. 16, pp. 6497-6502, 2005.

[19] J. W. Timmermans, T. M. Slaghek, M. Iizuka, W. van den Ende, J. de Roover, and A. van Laere, "Isolation and structural analysis of new fructans produced by chicory," Journal of Carbohydrate Chemistry, vol. 20, no. 5, pp. 375-395, 2001.

[20] S. Shah, A. Mahmood, S. Saied, and A. Malik, "Analysis and phytotoxicity of oily fraction of aerial parts of Cichorium intybus," Journal of the Chemical Society of Pakistan, vol. 34, no. 6, pp. 1464-1467, 2012.
[21] T. G. Tutin, V. H. Heywood, N. A. Burges et al., Flora Europaea 1, Cambridge University Press, 1964.

[22] R. Re, N. Pellegrini, A. Proteggente, A. Pannala, M. Yang, and C. Rice-Evans, "Antioxidant activity applying an improved ABTS radical cation decolorization assay," Free Radical Biology and Medicine, vol. 26, no. 9-10, pp. 1231-1237, 1999.

[23] C. M. Cantín, M. A. Moreno, and Y. Gogorcena, "Evaluation of the antioxidant capacity, phenolic compounds, and vitamin C content of different peach and nectarine (Prunus persica (L.) Batsch) breeding progenies," Journal of Agricultural and Food Chemistry, vol. 57, no. 11, pp. 4586-4592, 2009.

[24] G. Xu, D. Liu, J. Chen, X. Ye, Y. Ma, and J. Shi, "Juice components and antioxidant capacity of citrus varieties cultivated in China," Food Chemistry, vol. 106, no. 2, pp. 545-551, 2008.

[25] J. Zhishen, T. Mengcheng, and W. Jianming, "The determination of flavonoid contents in mulberry and their scavenging effects on superoxide radicals," Food Chemistry, vol. 64, no. 4, pp. 555559, 1999.

[26] P. D. Fraser, M. E. S. Pinto, D. E. Holloway, and P. M. Bramley, "Application of high-performance liquid chromatography with photodiode array detection to the metabolic profiling of plant isoprenoids," The Plant Journal, vol. 24, no. 4, pp. 551-558, 2000.

[27] M. Durante, M. S. Lenucci, L. D’Amico, G. Piro, and G. Mita, "Effect of drying and co-matrix addition on the yield and quality of supercritical $\mathrm{CO}_{2}$ extracted pumpkin (Cucurbita moschata Duch.) oil," Food Chemistry, vol. 148, pp. 314-320, 2014.

[28] J. Pérez-Jiménez, S. Arranz, M. Tabernero et al., "Updated methodology to determine antioxidant capacity in plant foods, oils and beverages: extraction, measurement and expression of results," Food Research International, vol. 41, no. 3, pp. 274-285, 2008.

[29] L. Müller, S. Gnoyke, A. M. Popken, and V. Böhm, "Antioxidant capacity and related parameters of different fruit formulations," LWT_Food Science and Technology, vol. 43, no. 6, pp. 992-999, 2010.

[30] L. Sinkovič, L. Demšar, D. Žnidarčič, R. Vidrih, J. Hribar, and D. Treutter, "Phenolic profiles in leaves of chicory cultivars (Cichorium intybus L.) as influenced by organic and mineral fertilizers," Food Chemistry, vol. 166, pp. 507-513, 2015.

[31] A. Chaoui, S. Mazhoudi, M. H. Ghorbal, and E. El Ferjani, "Cadmium and zinc induction of lipid peroxidation and effects on antioxidant enzyme activities in bean (Phaseolus vulgaris L.)," Plant Science, vol. 127, no. 2, pp. 139-147, 1997.

[32] Y. X. Chen, Y. F. He, Y. M. Luo, Y. L. Yu, Q. Lin, and M. H. Wong, "Physiological mechanism of plant roots exposed to cadmium," Chemosphere, vol. 50, no. 6, pp. 789-793, 2003.

[33] S. S. Gill and N. Tuteja, "Reactive oxygen species and antioxidant machinery in abiotic stress tolerance in crop plants," Plant Physiology and Biochemistry, vol. 48, no. 12, pp. 909-930, 2010.

[34] I. Tlili, C. Hdider, M. S. Lenucci, R. Ilahy, H. Jebari, and G. Dalessandro, "Bioactive compounds and antioxidant activities during fruit ripening of watermelon cultivars," Journal of Food Composition and Analysis, vol. 24, no. 7, pp. 923-928, 2011.

[35] S. Schaffer, S. Schmitt-Schillig, W. E. Müller, and G. P. Eckert, "Antioxidant properties of Mediterranean food plant extracts: geographical differences," Journal of Physiology and Pharmacology, vol. 56, supplement 1, pp. 115-124, 2005.

[36] F. Chinnici, A. Bendini, A. Gaiani, and C. Riponi, "Radical scavenging activities of peels and pulps from cv. golden delicious apples as related to their phenolic composition," Journal of Agricultural and Food Chemistry, vol. 52, no. 15, pp. 4684-4689, 2004. 
[37] I. Tlili, C. Hdider, M. S. Lenucci, I. Riadh, H. Jebari, and G. Dalessandro, "Bioactive compounds and antioxidant activities of different watermelon (Citrullus lanatus (Thunb.) Mansfeld) cultivars as affected by fruit sampling area," Journal of Food Composition and Analysis, vol. 24, no. 3, pp. 307-314, 2011.

[38] I. Parejo, F. Viladomat, J. Bastida et al., "Comparison between the radical scavenging activity and antioxidant activity of six distilled and nondistilled mediterranean herbs and aromatic plants," Journal of Agricultural and Food Chemistry, vol. 50, no. 23, pp. 6882-6890, 2002.

[39] M. M. Calvo, "Lutein: a valuable ingredient of fruit and vegetables," Critical Reviews in Food Science and Nutrition, vol. 45, no. 7-8, pp. 671-696, 2005.

[40] R. Lakshminarayana, M. Raju, T. P. Krishnakantha, and V. Baskaran, "Determination of major carotenoids in a few Indian leafy vegetables by high-performance liquid chromatography," Journal of Agricultural and Food Chemistry, vol. 53, no. 8, pp. 2838-2842, 2005.

[41] D. Žnidarčič, D. Ban, and H. Šircelj, "Carotenoid and chlorophyll composition of commonly consumed leafy vegetables in Mediterranean countries," Food Chemistry, vol. 129, no. 3, pp. 1164-1168, 2011.

[42] M. Kimura and D. B. Rodriguez-Amaya, "A scheme for obtaining standards and HPLC quantification of leafy vegetable carotenoids," Food Chemistry, vol. 78, no. 3, pp. 389-398, 2002.

[43] H. van den Berg, R. Faulks, H. F. Granado et al., "The potential for the improvement of carotenoid levels in foods and the likely systemic effects," Journal of the Science of Food and Agriculture, vol. 80, no. 7, pp. 880-912, 2000.

[44] L. Sanità di Toppi, E. Vurro, M. De Benedictis et al., "A bifasic response to cadmium stress in carrot: early acclimatory mechanisms give way to root collapse further to prolonged metal exposure," Plant Physiology and Biochemistry, vol. 58, pp. 269-279, 2012. 

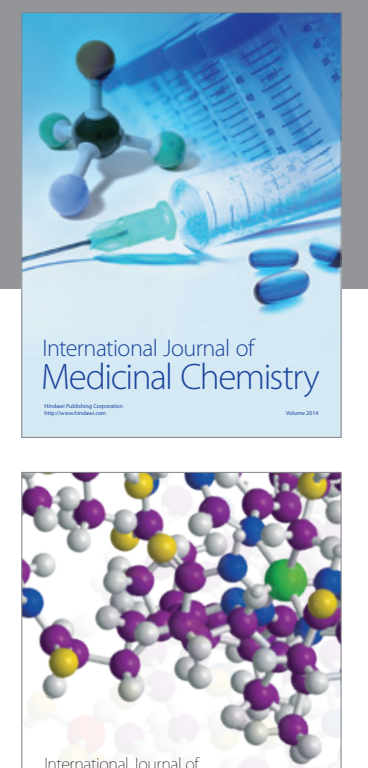

\section{Carbohydrate} Chemistry

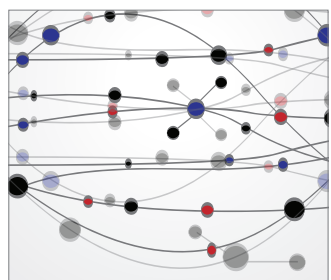

The Scientific World Journal
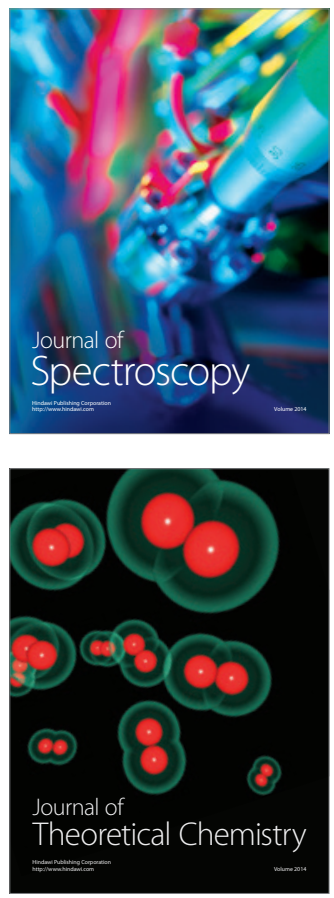
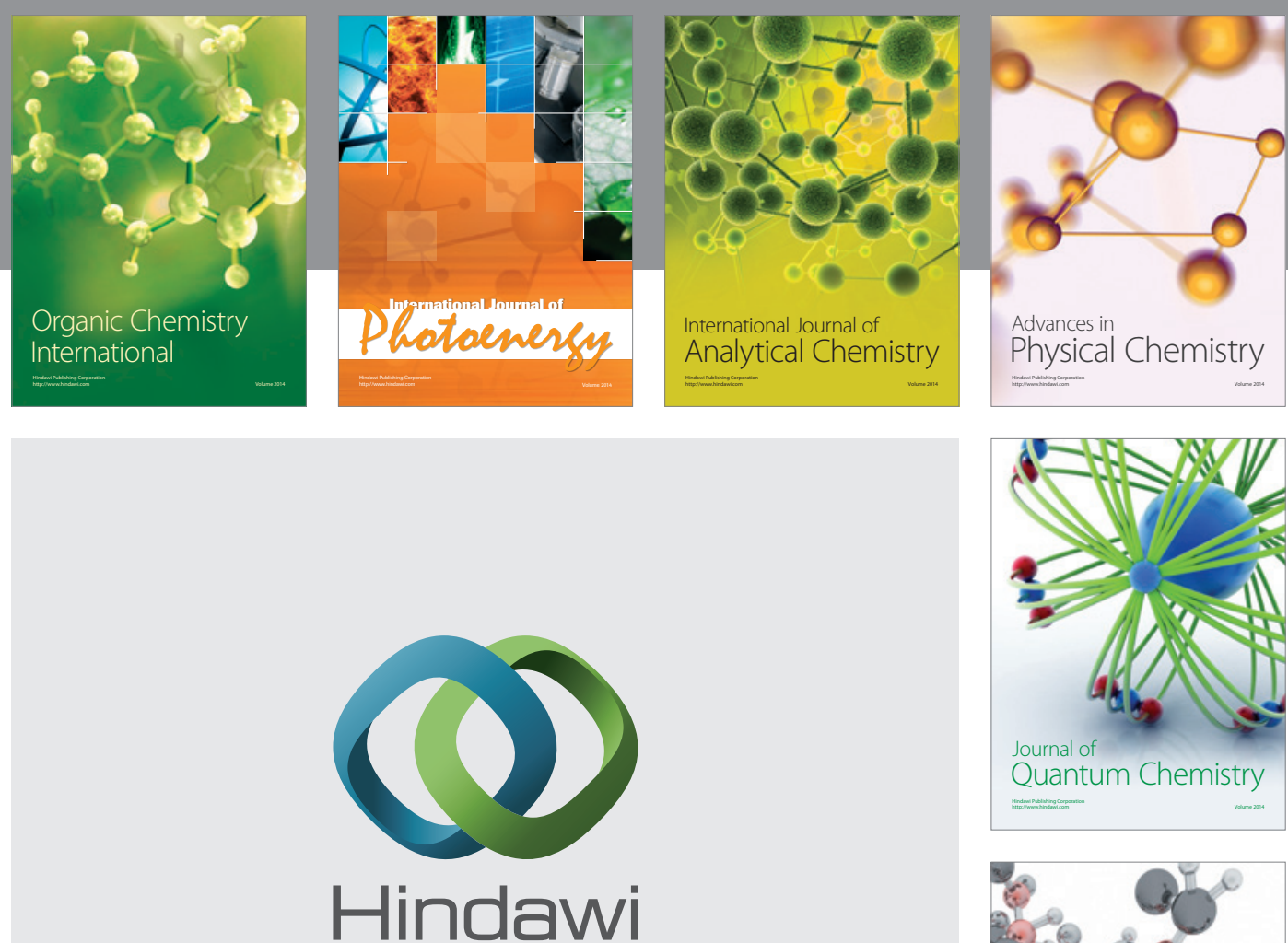

Submit your manuscripts at

http://www.hindawi.com

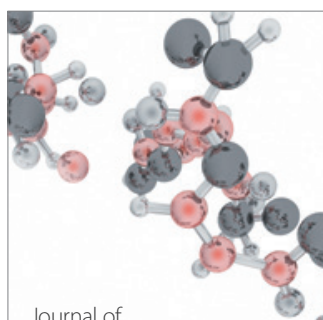

Analytical Methods

in Chemistry

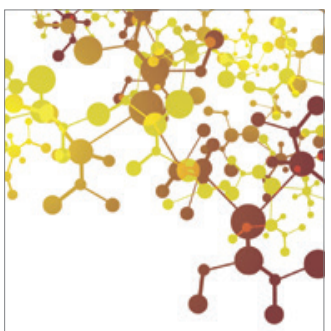

Journal of

Applied Chemistry

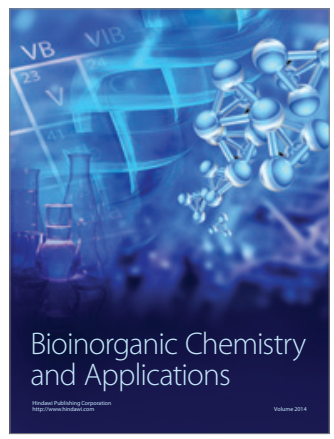

Inorganic Chemistry
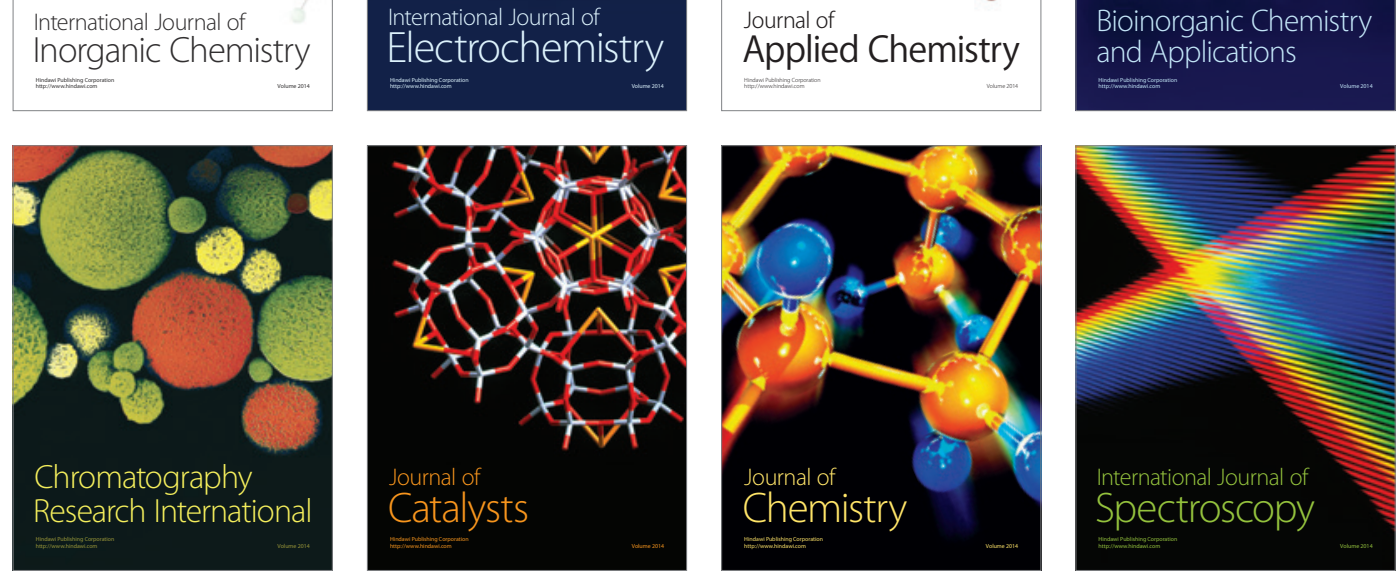